\title{
Can Adult Neurogenesis Be Considered as Neuroplasticity?
}

\author{
Hamidreza Famitafreshi ${ }^{1}$ and Morteza Karimian ${ }^{2,{ }^{*}}$ \\ ${ }^{1}$ Physiology Department, Tehran University of Medical Sciences-International Campus, Tehran, Iran \\ ${ }^{2}$ Physiology Department, Tehran University of Medical Sciences, Tehran, Iran \\ "Corresponding author: Physiology Department, Tehran University of Medical Sciences, Tehran, Iran. Fax: +98-2166419484, Email: karimian@tums.ac.ir \\ Received 2018 May 27; Revised 2019 January 31; Accepted 2019 October 23.
}

\begin{abstract}
Neuroplasticity is defined as adaptive changes in the sub-structures of synapses. Neuroplasticity is an important capability of the brain to respond to new stress. Stress can range from environmental changes to organic damages. Neurogenesis defined as the generation of new neurons in some parts of brain regions, especially the dentate gyrus of the hippocampus and sub-ventricular zone, can be considered as neuroplasticity. Neurogenesis facilitates the brain's adaptive response to new stress by integrating new neurons into related areas. In this review, we recall some aspects of neurogenesis that may be considered as neuroplasticity.
\end{abstract}

Keywords: Neuroplasticity, Neurogenesis, Stress, Memory, Hippocampus, Stroke

\section{Context}

Neuroplasticity refers to changes in the neuronal function as the consequence of the ever-changing environment (1). It means that as long as environmental changes persist, the changes in neuronal function persist(2). Therefore, the adaptation to the alternation of the environment causes neurons to change their functions as the consequence of synaptic changes (3). The changes in synapses can alter neuronal function in such a way that they adapt to the new condition (4). Since this phenomenon is present in all parts of the nervous system, it causes a wide variety of outcomes in different parts of the central nervous system (CNS) (4-6). Neurogenesis defined as the production of new neurons is associated with the alternation of brain function; thus, neurogenesis can be considered as neuroplasticity that changes in accordance with some conditions (7).

\section{Neurogenesis}

Neurogenesis is defined as the production of new neurons in some parts of brain regions (8-10). Neurogenesis occurs in some parts of brain regions including the subventricular zone (7), dentate gyrus (7), striatum (11), and substantia nigra (12). Neurogenesis in the olfactory bulb is considered a very quiescent phenomenon (13). Neurogenesis reduces with increasing age (9). One of the important aspects of neurogenesis that might be considered as neuroplasticity is the continuous generation of new neurons accompanied by behavioral changes. We know that neuroplasticity is defined as changes in synaptic structures (14) and the addition of new neurons to previous existing neurons is a less specific definition. However, based on new experiments that considered a function for all neuronal subtypes including neurons in all stages of maturation, neurogenesis can be considered as neuroplasticity(15). From this view, a newly born immature neuron has a specific function that is different from the function of mature neurons (16). Moreover, if we consider that adaptation to the environment that is one of the most striking features of neuroplasticity (17) also occurs in neurogenesis, neurogenesis in this regard can be considered as neuroplasticity.

\section{About the Generation of New Neurons}

The concept of neurogenesis is derived from Altman studies that proposed for the first time that new neurons in later adulthood are generated in some parts of the brain region (18). Later on, many studies were performed to find out the nature of this phenomenon. The origin of newly born neurons in the CNS is thought glial-derived cells. Experiments have shown that a glial-like cell is a primary cell in this regard. This glial-like cell will eventually be differentiated into both glial cells and mature neurons (19). However, an important point in this regard is to answer the question that what are the characteristics of new neurons that are integrated into pre-exciting circuits. There is an important question about the direction of migration that is an important determinant of fates of newly born neurons. For example, radially directed migrating neurons eventually show interneuron characteristics (20). The ma- 
jority of these cells will show GABAergic, dopaminergic, and glutamatergic neurons (21). Immature neurons will be integrated into the pre-existing circuit and become mature. There is a difference in the fate of newly born neurons in different parts of the CNS. In dentate gyrus of the hippocampus, immature neurons will develop new processes such as dendrites and axons that are necessary for integrating into new circuits (22). GABAergic interneurons have a critical role in activating the quiescent neurons (23). Of course for the generation of new neurons, efficient neurogenic niches are necessary (7). They are composed of various cells such as endothelial cells, different types of glial neurons, and ependymal cells. These niches must be efficacious for neurogenesis.

\section{Neurogenesis and Stress}

Stress is defined as any issue that causes hemostasis to alter and this, in turn, causes the body to respond in several manners to keep hemostasis in equilibrium (24). In this regard, allostasis is the reaction of the body to stress to keep the body in a steady-state (25). In this sense, adaptation occurs to combat unwanted stress $(26,27)$. One of the main responses of the body to stress is changes in neurogenesis to neutralize the stress (28-30). In different paradigms of behavioral experiment, it has been shown that stress will influence neurogenesis and causes psychiatric symptom development and in many others, the symptoms will not develop $(31,32)$. The hippocampus is a brain region known to be important to combat the negative effects of stress (31, 33). Neurogenesis that occurs in the hippocampus plays an important role in this regard. Neurogenesis in the hippocampus has shown to be important for the regulation of many stress response phenomena (34). The evidence that supports this theory is that many stress-exposed animals will eventually develop anxiety-related disorders (35). However, many of them will not develop anxiety-related responses $(36,37)$. This is probably because molecular mechanisms that regulate neurogenesis interfere with the severity of the response to stress (38).

\section{Neurogenesis and Psychiatric Disorders}

Psychiatric disorders encompass a great proportion of human diseases (39). Neurogenesis can control the development of psychiatric disorders and this may offer neurogenesis a regulator function (40). It may be considered as neuroplasticity. Neurogenesis alternation can alleviate many psychiatric disorders (41-44). Depression as one of the most common diseases has shown to be alleviated with increasing neurogenesis (45). However, other psychiatric diseases may benefit by increasing neurogenesis.
For example, schizophrenic patients may benefit from antipsychotic drugs by increasing neurogenesis (46). Posttraumatic stress disorder (PTSD), uncontrollable expression of fear in neutral and safe environments may benefit from the improvement of neurogenesis (47). An important concept in this regard is that hippocampal neurogenesis can modulate emotional responses (48). Other anxiety-related disorders can be influenced by hippocampal neurogenesis (49). An important point in this regard is that many psychiatric diseases co-morbid with another one (50-52). Thus, there is strong evidence that neurogenesis is a modulator or at least can alleviate psychiatric comorbidities. Also, drug addiction is another reflection of this issue. Overall, drugs are the most potent modulators of neurogenesis to suppress it $(53,54)$. The suppression of neurogenesis, in turn, may cause various psychiatric comorbidities such as depression and anxiety disorders (55, 56).

\section{Neurogenesis and Cognition}

Memory and cognition as essential functions of the brain that are necessary for life are regulated by neurogenesis $(57,58)$. Memory formation involves some parts of brain regions (59). Neurogenesis in the hippocampus is a dynamic process that improves memory with the addition of new neurons (60). It has been shown that the improvement of memory with various drugs is accompanied by an increase in neurogenesis $(61,62)$. The complex nature of memory formation inside the hippocampus offers neurogenesis a neuroplasticity function. Memory formation inside the hippocampus involves all parts of the hippocampus encompassing the dentate gyrus of the hippocampus, CA1, CA2, CA3, and CA4 (63-65). The integration of new neurons to all parts of this circuit will improve memory (66). Memory is an important brain function that is needed for adaption to the new environment probably by avoiding unwanted stressors (67-69). Memory is necessary for various functions and neurogenesis has an important adaptive function in memory regulation. The flexibility of cognition is an important concept that offers the hippocampus an important ability to cope with various situations $(70,71)$. A common issue in this regard is the pattern separation $(72,73)$.

\section{Neurogenesis and Stroke}

Besides the hippocampus, neurogenesis occurs in other parts of the brain such as the sub-ventricular zone (74). Experiments have shown that the improvement of neurogenesis in the sub-ventricular zone (75) and striatum (76) in the infarcted area significantly reduces the infarct 
size. However, the improvement of stroke with improving neurogenesis through various mechanisms may signify the role of mediators that confer neuronal maturation and alternation in peri-infarcted areas (77-79). Stoke as the second leading cause of death (80) is an important issue to be studied and the sub-ventricular zone and striatal neurogenesis derive many defensive mechanisms in this regard.

\section{Neurogenesis in Other Areas}

In addition to the dentate gyrus of the hippocampus and sub-ventricular zone, neurogenesis also occurs in the striatum (11) and substantia nigra (12). The occurrence of neurogenesis in other areas besides the two mentioned areas may signify the importance of this phenomenon for the brain to show a great potential to regenerate the injured and impaired areas. Other places besides the mentioned areas are plausible for neurogenesis. This reflects the adaptive function capabilities of the brain to stress and unwanted injuries.

\section{Conclusions}

Overall, the importance of neurogenesis in brain function was discussed. Neurogenesis plays an important role in regenerating the injured areas of the brain. It may give the brain an additional function and may strengthen its existing functions. It should be noted that when there is no stress, neurogenesis is a quiescent phenomenon with no definite function. Therefore, it cannot be considered as neuroplasticity to help the brain overcome the stress. Neuroplasticity defined as the alternation of the brain in response to new stress can be used for neurogenesis since neurogenesis prepares the brain to face new stress that may be opposed to life.

\section{Footnotes}

Authors' Contribution: This manuscript was written in collaboration between two authors. Hamidreza Famitafreshi selected the subject, collected the references, and wrote the first draft of the manuscript with the assistance of Morteza Karimian. Both authors read and approved the final draft of the manuscript.

Conflict of Interests: None to declare.

Ethical Approval: The reference code was 91-01-159-18022, Tehran, Iran.

Funding/Support: None to report. This research was conducted by personal funding.

\section{References}

1. Kerr AL, Cheng SY, Jones TA. Experience-dependent neural plasticity in the adult damaged brain. J Commun Disord. 2011;44(5):538-48. doi: 10.1016/j.jcomdis.2011.04.011. [PubMed: 21620413]. [PubMed Central: PMC3162127].

2. Huttenlocher PR. Neural plasticity: The effects of environment on the development of the cerebral cortex. USA: Harvard University Press; 2009.

3. Luscher C, Malenka RC. Drug-evoked synaptic plasticity in addiction: From molecular changes to circuit remodeling. Neuron. 2011;69(4):650-63. doi: 10.1016/j.neuron.2011.01.017. [PubMed: 21338877]. [PubMed Central: PMC4046255].

4. Deppermann S, Storchak H, Fallgatter AJ, Ehlis AC. Stress-induced neuroplasticity: (Mal)Adaptation to adverse life events in patients with PTSD-a critical overview. Neuroscience. 2014;283:166-77. doi: 10.1016/j.neuroscience.2014.08.037. [PubMed: 25193848].

5. Wilder-Smith OH, Tassonyi E, Arendt-Nielsen L. Preoperative back pain is associated with diverse manifestations of central neuroplasticity. Pain. 2002;97(3):189-94. doi: 10.1016/s0304-3959(01)00430-4. [PubMed: 12044615].

6. Manji HK, Duman RS. Impairments of neuroplasticity and cellular resilience in severe mood disorders: Implications for the development of novel therapeutics. Psychopharmacol Bull. 2001;35(2):5-49. [PubMed: 12397885].

7. Ming GL, Song H. Adult neurogenesis in the mammalian brain: Significant answers and significant questions. Neuron. 2011;70(4):687-702. doi: 10.1016/j.neuron.2011.05.001. [PubMed: 21609825]. [PubMed Central: PMC3106107].

8. Knoth R, Singec I, Ditter M, Pantazis G, Capetian P, Meyer RP, et al. Murine features of neurogenesis in the human hippocampus across the lifespan from 0 to 100 years. PLoS One. 2010;5(1). e8809. doi: 10.1371/journal.pone.0008809. [PubMed: 20126454]. [PubMed Central: PMC2813284].

9. Sanai N, Nguyen T, Ihrie RA, Mirzadeh Z, Tsai HH, Wong M, et al. Corridors of migrating neurons in the human brain and their decline during infancy. Nature. 2011;478(7369):382-6. doi: 10.1038/nature10487. [PubMed: 21964341]. [PubMed Central: PMC3197903].

10. Wang C, Liu F, Liu YY, Zhao $\mathrm{CH}$, You Y, Wang L, et al. Identification and characterization of neuroblasts in the subventricular zone and rostral migratory stream of the adult human brain. Cell Res. 2011;21(11):1534-50. doi: 10.1038/cr.2011.83. [PubMed: 21577236]. [PubMed Central: PMC3365638].

11. Ernst A, Alkass K, Bernard S, Salehpour M, Perl S, Tisdale J, et al. Neurogenesis in the striatum of the adult human brain. Cell. 2014;156(5):1072-83. doi: 10.1016/j.cell.2014.01.044. [PubMed: 24561062].

12. Zhao M, Momma S, Delfani K, Carlen M, Cassidy RM, Johansson $\mathrm{CB}$, et al. Evidence for neurogenesis in the adult mammalian substantia nigra. Proc Natl Acad Sci USA. 2003;100(13):7925-30. doi: 10.1073/pnas.1131955100. [PubMed: 12792021]. [PubMed Central: PMC164689].

13. Bergmann O, Liebl J, Bernard S, Alkass K, Yeung MS, Steier P, et al. The age of olfactory bulb neurons in humans. Neuron. 2012;74(4):634-9. doi: 10.1016/j.neuron.2012.03.030. [PubMed: 22632721].

14. Demey I, Allegri RF, Barrera-Valencia M. Neurobiological basis of rehabilitation. Ces psicología. 2014;7(1):130-40.

15. Kempermann G, Wiskott L, Gage FH. Functional significance of adult neurogenesis. Curr Opin Neurobiol. 2004;14(2):186-91. doi: 10.1016/j.conb.2004.03.001. [PubMed: 15082323].

16. Kempermann G, Jessberger S, Steiner B, Kronenberg G. Milestones of neuronal development in the adult hippocampus. Trends Neurosci. 2004;27(8):447-52. doi: 10.1016/j.tins.2004.05.013. [PubMed: 15271491].

17. Munte TF, Altenmuller E, Jancke L. The musician's brain as a model of neuroplasticity. Nat Rev Neurosci. 2002;3(6):473-8. doi:10.1038/nrn843. [PubMed: 12042882]. 
18. Altman J, Das GD. Autoradiographic and histological evidence of postnatal hippocampal neurogenesis in rats. J Comp Neurol. 1965;124(3):319-35. doi: 10.1002/cne.901240303. [PubMed: 5861717]

19. Lois C, Garcia-Verdugo JM, Alvarez-Buylla A. Chain migration of neuronal precursors. Science. 1996;271(5251):978-81. doi: 10.1126/science.271.5251.978. [PubMed: 8584933].

20. Lledo PM, Alonso M, Grubb MS. Adult neurogenesis and functional plasticity in neuronal circuits. Nat Rev Neurosci. 2006;7(3):179-93. doi: 10.1038/nrn1867. [PubMed: 16495940].

21. Brill MS, Ninkovic J, Winpenny E, Hodge RD, Ozen I, Yang R, et al. Adult generation of glutamatergic olfactory bulb interneurons. Nat Neurosci. 2009;12(12):1524-33. doi: 10.1038/nn.2416. [PubMed: 19881504]. [PubMed Central: PMC2787799].

22. Zhao C, Teng EM, Summers R Jr, Ming GL, Gage FH. Distinct morphological stages of dentate granule neuron maturation in the adult mouse hippocampus. J Neurosci. 2006;26(1):3-11. doi: 10.1523/JNEUROSCI.3648-05.2006. [PubMed: 16399667]. [PubMed Central: PMC6674324].

23. Bhattacharyya BJ, Banisadr G, Jung H, Ren D, Cronshaw DG, Zou Y, et al. The chemokine stromal cell-derived factor-1 regulates GABAergic inputs to neural progenitors in the postnatal dentate gyrus. J Neurosci. 2008;28(26):6720-30. doi: 10.1523/JNEUROSCI.1677-08.2008. [PubMed: 18579746]. [PubMed Central: PMC2720755].

24. de Kloet ER, Joels M, Holsboer F. Stress and the brain: From adaptation to disease. Nat Rev Neurosci. 2005;6(6):463-75. doi: 10.1038/nrn1683. [PubMed: 15891777].

25. Day TA. Defining stress as a prelude to mapping its neurocircuitry: No help from allostasis. Prog Neuropsychopharmacol Biol Psychiatry. 2005;29(8):1195-200. doi: 10.1016/j.pnpbp.2005.08.005. [PubMed: 16213079].

26. Bijlsma R, Loeschcke V. Environmental stress, adaptation and evolution: An overview. J Evol Biol. 2005;18(4):744-9. doi: 10.1111/j.14209101.2005.00962.x. [PubMed: 16033544].

27. Levone BR, Cryan JF, O'Leary OF. Role of adult hippocampal neurogenesis in stress resilience. Neurobiol Stress. 2015;1:147-55. doi: 10.1016/j.ynstr.2014.11.003. [PubMed: 27589664]. [PubMed Central: PMC4721321].

28. Snyder JS, Soumier A, Brewer M, Pickel J, Cameron HA. Adult hippocampal neurogenesis buffers stress responses and depressive behaviour. Nature. 2011;476(7361):458-61. doi: 10.1038/nature10287. [PubMed: 21814201]. [PubMed Central: PMC3162077].

29. Mirescu C, Peters JD, Gould E. Early life experience alters response of adult neurogenesis to stress. Nat Neurosci. 2004;7(8):841-6. doi: 10.1038/nn1290. [PubMed: 15273691].

30. Mirescu C, Gould E. Stress and adult neurogenesis. Hippocampus. 2006;16(3):233-8. doi: 10.1002/hipo.20155. [PubMed: 16411244].

31. Warner-Schmidt JL, Duman RS. Hippocampal neurogenesis: Opposing effects of stress and antidepressant treatment. Hippocampus. 2006;16(3):239-49. doi:10.1002/hipo.20156. [PubMed: 16425236].

32. Jacobs BL, van Praag H, Gage FH. Adult brain neurogenesis and psychiatry: A novel theory of depression. Mol Psychiatry. 2000;5(3):262-9. doi: $10.1038 /$ sj.mp.4000712. [PubMed: 10889528].

33. McEwen BS. Stress and hippocampal plasticity. Annu Rev Neurosci. 1999;22:105-22. doi: 10.1146/annurev.neuro.22.1.105. [PubMed: 10202533].

34. Dranovsky A, Hen R. Hippocampal neurogenesis: Regulation by stress and antidepressants. Biol Psychiatry. 2006;59(12):1136-43. doi: 10.1016/j.biopsych.2006.03.082. [PubMed: 16797263].

35. Lemaire V, Koehl M, Le Moal M, Abrous DN. Prenatal stress produces learning deficits associated with an inhibition of neurogenesis in the hippocampus. Proc Natl Acad Sci U S A. 2000;97(20):11032-7. doi: 10.1073/pnas.97.20.11032. [PubMed: 11005874]. [PubMed Central: PMC27143].

36. Zhao C, Deng W, Gage FH. Mechanisms and functional implications of adult neurogenesis. Cell. 2008;132(4):645-60. doi: 10.1016/j.cell.2008.01.033. [PubMed: 18295581].
37. Charney DS, Manji HK. Life stress, genes, and depression: Multiple pathways lead to increased risk and new opportunities for intervention. Sci STKE. 2004;2004(225):re5. doi: 10.1126/stke.2252004re5. [PubMed: 15039492].

38. Mahar I, Bambico FR, Mechawar N, Nobrega JN. Stress, serotonin, and hippocampal neurogenesis in relation to depression and antidepressant effects. Neurosci Biobehav Rev. 2014;38:173-92. doi 10.1016/j.neubiorev.2013.11.009. [PubMed: 24300695].

39. Whiteford HA, Degenhardt L, Rehm J, Baxter AJ, Ferrari AJ, Erskine HE, et al. Global burden of disease attributable to mental and substance use disorders: Findings from the Global Burden of Disease study 2010. Lancet. 2013;382(9904):1575-86. doi: 10.1016/S0140-6736(13)616116. [PubMed: 23993280].

40. Jun H, Mohammed Qasim Hussaini S, Rigby MJ, Jang MH. Functional role of adult hippocampal neurogenesis as a therapeutic strategy for mental disorders. Neural Plast. 2012;2012:854285. doi: 10.1155/2012/854285. [PubMed: 23346419]. [PubMed Central PMC3549353].

41. DeCarolis NA, Eisch AJ. Hippocampal neurogenesis as a target for the treatment of mental illness: A critical evaluation. Neuropharmacology. 2010;58(6):884-93. doi: 10.1016/j.neuropharm.2009.12.013. [PubMed: 20060007]. [PubMed Central: PMC2839019].

42. Krishnan V, Nestler EJ. The molecular neurobiology of depression Nature. 2008;455(7215):894-902. doi: 10.1038/nature07455. [PubMed: 18923511]. [PubMed Central: PMC2721780].

43. Peng Q, Masuda N, Jiang M, Li Q, Zhao M, Ross CA, et al. The antidepressant sertraline improves the phenotype, promotes neurogenesis and increases BDNF levels in the R6/2 Huntington's disease mouse model. Exp Neurol. 2008;210(1):154-63. doi: 10.1016/j.expneurol.2007.10.015. [PubMed: 18096160]. [PubMed Central: PMC2278120].

44. Lagace DC, Donovan MH, DeCarolis NA, Farnbauch LA, Malhotra $\mathrm{S}$, Berton $\mathrm{O}$, et al. Adult hippocampal neurogenesis is functionally important for stress-induced social avoidance. Proc Natl Acad Sci USA. 2010;107(9):4436-41. doi: 10.1073/pnas.0910072107. [PubMed: 20176946]. [PubMed Central: PMC2840117].

45. Schmidt HD, Duman RS. The role of neurotrophic factors in adult hippocampal neurogenesis, antidepressant treatments and animal models of depressive-like behavior. Behav Pharmacol. 2007;18(5 6):391-418. doi: 10.1097/FBP.ob013e3282ee2aa8. [PubMed: 17762509].

46. Reif A, Fritzen S, Finger M, Strobel A, Lauer M, Schmitt A, et al. Neural stem cell proliferation is decreased in schizophrenia, but not in depression. Mol Psychiatry. 2006;11(5):514-22. doi:10.1038/sj.mp.4001791. [PubMed: 16415915].

47. Kheirbek MA, Klemenhagen KC, Sahay A, Hen R. Neurogenesis and generalization: A new approach to stratify and treat anxiety disorders. Nat Neurosci. 2012;15(12):1613-20. doi: 10.1038/nn.3262. [PubMed 23187693]. [PubMed Central: PMC3638121].

48. Oomen CA, Soeters H, Audureau N, Vermunt L, van Hasselt FN, Manders EM, et al. Severe early life stress hampers spatial learning and neurogenesis, but improves hippocampal synaptic plasticity and emotional learning under high-stress conditions in adulthood. $J$ Neurosci. 2010;30(19):6635-45. doi: 10.1523/JNEUROSCI.0247-10.2010. [PubMed: 20463226]. [PubMed Central: PMC6632559].

49. Ageta H, Murayama A, Migishima R, Kida S, Tsuchida K, Yokoyama $\mathrm{M}$, et al. Activin in the brain modulates anxiety-related behavior and adult neurogenesis. PLoS One. 2008;3(4). e1869. doi: 10.1371/journal.pone.0001869. [PubMed: 18382659]. [PubMed Central: PMC2270335].

50. Chouinard G, Beauclair L, Belanger MC. Gabapentin: Long-term antianxiety and hypnotic effects in psychiatric patients with comorbid anxiety-related disorders. Can J Psychiatry. 1998;43(3):305. [PubMed: 9561320].

51. Conway KP, Compton W, Stinson FS, Grant BF. Lifetime comorbidity of DSM-IV mood and anxiety disorders and specific drug use disorders: results from the National Epidemiologic Survey on alcohol and related conditions. J Clin Psychiatry. 2006;67(2):247-57. doi 
10.4088/jcp.v67n0211. [PubMed: 16566620].

52. Petry NM, Stinson FS, Grant BF. Comorbidity of DSM-IV pathological gambling and other psychiatric disorders: Results from the $\mathrm{Na}$ tional Epidemiologic survey on alcohol and related conditions. J Clin Psychiatry. 2005;66(5):564-74. doi: 10.4088/jcp.v66n0504. [PubMed: 15889941].

53. Eisch AJ, Harburg GC. Opiates, psychostimulants, and adult hippocampal neurogenesis: Insights for addiction and stem cell biology. Hippocampus. 2006;16(3):271-86. doi: 10.1002/hipo.20161. [PubMed 16411230].

54. Noonan MA, Bulin SE, Fuller DC, Eisch AJ. Reduction of adult hippocampal neurogenesis confers vulnerability in an animal model of cocaine addiction. J Neurosci. 2010;30(1):304-15. doi: 10.1523/JNEUROSCI.4256-09.2010. [PubMed: 20053911]. [PubMed Central: PMC2844797].

55. Petrik D, Lagace DC, Eisch AJ. The neurogenesis hypothesis of affective and anxiety disorders: Are we mistaking the scaffolding for the building? Neuropharmacology. 2012;62(1):21-34. doi: 10.1016/j.neuropharm.2011.09.003. [PubMed: 21945290]. [PubMed Central: PMC3698048].

56. Leweke FM, Koethe D. Cannabis and psychiatric disorders: It is not only addiction. Addict Biol. 2008;13(2):264-75. doi: 10.1111/j.13691600.2008.00106.x. [PubMed: 18482435].

57. Veyrac A, Sacquet J, Nguyen V, Marien M, Jourdan F, Didier A. Novelty determines the effects of olfactory enrichment on memory and neurogenesis through noradrenergic mechanisms. Neuropsychopharmacology. 2009;34(3):786-95. doi: 10.1038/npp.2008.191. [PubMed 18946468].

58. Ben Menachem-Zidon O, Goshen I, Kreisel T, Ben Menahem Y, Reinhartz E, Ben Hur T, et al. Intrahippocampal transplantation of transgenic neural precursor cells overexpressing interleukin-1 receptor antagonist blocks chronic isolation-induced impairment in memory and neurogenesis. Neuropsychopharmacology. 2008;33(9):2251-62. doi: 10.1038/sj.npp.1301606. [PubMed: 17987063].

59. Izquierdo I, Medina JH. Memory formation: The sequence of biochemical events in the hippocampus and its connection to activity in other brain structures. Neurobiol Learn Mem. 1997;68(3):285-316. doi 10.1006/nlme.1997.3799. [PubMed: 9398590]

60. Deng W, Aimone JB, Gage FH. New neurons and new memories: How does adult hippocampal neurogenesis affect learning and memory? Nat Rev Neurosci. 2010;11(5):339-50. doi: 10.1038/nrn2822. [PubMed 20354534]. [PubMed Central: PMC2886712].

61. Lu D, Mahmood A, Qu C, Goussev A, Schallert T, Chopp M. Erythropoietin enhances neurogenesis and restores spatial memory in rats after traumatic brain injury. J Neurotrauma. 2005;22(9):1011-7. doi 10.1089/neu.2005.22.1011. [PubMed: 16156716].

62. Marchalant Y, Baranger K, Wenk GL, Khrestchatisky M, Rivera S. Can the benefits of cannabinoid receptor stimulation on neuroinflammation, neurogenesis and memory during normal aging be useful in $\mathrm{AD}$ prevention? J Neuroinflammation. 2012;9:10. doi: 10.1186/1742-2094-910. [PubMed: 22248015]. [PubMed Central: PMC3284401].

63. Blum S, Moore AN, Adams F, Dash PK. A mitogen-activated protein kinase cascade in the CA1/CA2 subfield of the dorsal hippocampus is essential for long-term spatial memory. J Neurosci. 1999;19(9):3535-44. [PubMed: 10212313]. [PubMed Central: PMC6782236].

64. Poser S, Storm DR. Role of Ca2+-stimulated adenylyl cyclases in LTP and memory formation. Int J Dev Neurosci. 2001;19(4):387-94. doi: 10.1016/s0736-5748(00)00094-0. [PubMed: 11378299].

65. Nakazawa K, Quirk MC, Chitwood RA, Watanabe M, Yeckel MF, Sun LD, et al. Requirement for hippocampal CA3 NMDA receptors in associative memory recall. Science. 2002;297(5579):211-8. doi:10.1126/science.1071795. [PubMed: 12040087]. [PubMed Central: PMC2877140].
66. Ramirez-Amaya V, Marrone DF, Gage FH, Worley PF, Barnes CA. Integration of new neurons into functional neural networks. J Neurosci. 2006;26(47):12237-41. doi:10.1523/JNEUROSCI.2195-06.2006. [PubMed: 17122048]. [PubMed Central: PMC6675440].

67. Kondratova AA, Dubrovsky YV, Antoch MP, Kondratov RV. Circadian clock proteins control adaptation to novel environment and memory formation. Aging (Albany NY). 2010;2(5):285-97. doi: 10.18632/aging.100142. [PubMed: 20519775]. [PubMed Central: PMC2898019].

68. Mori N.Adaptation to a changing environment by means of the memory based thermodynamical genetic algorithm. Proc 7th ICGA. 1998.

69. McEwen BS. Stress, sex, and neural adaptation to a changing environment: Mechanisms of neuronal remodeling. Ann N Y Acad Sci. 2010;1204 Suppl:E38-59. doi: 10.1111/j.1749-6632.2010.05568.x. [PubMed: 20840167]. [PubMed Central: PMC2946089].

70. Burghardt NS, Park EH, Hen R, Fenton AA. Adult-born hippocampal neurons promote cognitive flexibility in mice. Hippocampus. 2012;22(9):1795-808. doi: 10.1002/hipo.22013. [PubMed: 22431384]. [PubMed Central: PMC4784987].

71. Anacker C, Hen R. Adult hippocampal neurogenesis and cognitive flexibility - linking memory and mood. Nat Rev Neurosci. 2017;18(6):335-46. doi: 10.1038/nrn.2017.45. [PubMed: 28469276]. [PubMed Central: PMC6261347].

72. Sahay A, Scobie KN, Hill AS, O'Carroll CM, Kheirbek MA, Burghardt NS, et al. Increasing adult hippocampal neurogenesis is sufficient to improve pattern separation. Nature. 2011;472(7344):466-70. doi: 10.1038/nature09817. [PubMed: 21460835]. [PubMed Central: PMC3084370].

73. Chambers RA, Potenza MN, Hoffman RE, Miranker W. Simulated apoptosis/neurogenesis regulates learning and memory capabilities of adaptive neural networks. Neuropsychopharmacology. 2004;29(4):747-58. doi: 10.1038/sj.npp.1300358. [PubMed:14702022].

74. Alvarez-Buylla A, Garcia-Verdugo JM. Neurogenesis in adult subventricular zone. J Neurosci. 2002;22(3):629-34. [PubMed: 11826091]. [PubMed Central: PMC6758521].

75. Sun Y, Jin K, Xie L, Childs J, Mao XO, Logvinova A, et al. VEGF-induced neuroprotection, neurogenesis, and angiogenesis after focal cerebral ischemia. J Clin Invest. 2003;111(12):1843-51. doi: 10.1172/JCI17977. [PubMed: 12813020]. [PubMed Central: PMC161428].

76. Parent JM, Vexler ZS, Gong C, Derugin N, Ferriero DM. Rat forebrain neurogenesis and striatal neuron replacement after focal stroke. Ann Neurol. 2002;52(6):802-13. doi: 10.1002/ana.10393. [PubMed: 12447935].

77. Ma M, Ma Y, Yi X, Guo R, Zhu W, Fan X, et al. Intranasal delivery of transforming growth factor-beta1 in mice after stroke reduces infarct volume and increases neurogenesis in the subventricular zone. BMC Neurosci. 2008;9:117. doi: 10.1186/1471-2202-9-117. [PubMed: 19077183]. [PubMed Central: PMC2637876].

78. Ling L, Hou Q, Xing S, Yu J, Pei Z, Zeng J. Exogenous kallikrein enhances neurogenesis and angiogenesis in the subventricular zone and the peri-infarction region and improves neurological function after focal cortical infarction in hypertensive rats. Brain Res. 2008;1206:8997. doi: 10.1016/j.brainres.2008.01.099. [PubMed: 18353282].

79. Jin K, Sun Y, Xie L, Childs J, Mao XO, Greenberg DA. Post-ischemic administration of heparin-binding epidermal growth factor-like growth factor (HB-EGF) reduces infarct size and modifies neurogenesis after focal cerebral ischemia in the rat. $J$ Cereb Blood Flow Metab. 2004;24(4):399-408. doi: 10.1097/00004647-20040400000005. [PubMed: 15087709].

80. Towfighi A, Saver JL. Stroke declines from third to fourth leading cause of death in the United States: Historical perspective and challenges ahead. Stroke. 2011;42(8):2351-5. doi: 10.1161/STROKEAHA.111.621904. [PubMed: 21778445]. 